\title{
Variability of Tidal Volume in Patient-Triggered Mechanical Ventilation in ARDS
}

\author{
Sophie Perinel-Ragey MD, Loredana Baboi PhD, and Claude Guérin MD PhD
}

\begin{abstract}
BACKGROUND: Limiting tidal volume $\left(\mathrm{V}_{\mathrm{T}}\right)$ in patients with ARDS may not be achieved once patient-triggered breaths occur. Furthermore, ICU ventilators offer numerous patient-triggered modes that work differently across brands. We systematically investigated, using a bench model, the effect of patient-triggered modes on the size and variability of $\mathbf{V}_{\mathrm{T}}$ at different breathing frequencies (f), patient effort, and ARDS severity. METHODS: We used a V500 Infinity ICU ventilator connected to an ASL 5000 lung model whose compliance was mimicking mild, moderate, and severe ARDS. Thirteen patient-triggered modes were tested, falling into 3 categories, namely volume control ventilation with mandatory minute ventilation; pressure control ventilation, including airway pressure release ventilation (APRV); and pressure support ventilation. Two levels of $f$ and effort were tested for each ARDS severity in each mode. Median (first-third quartiles) $V_{T}$ was compared across modes using non-parametric tests. The probability of $V_{T}>6 \mathrm{~mL} / \mathrm{kg}$ ideal body weight was assessed by binomial regression and expressed as the odds ratio (OR) with $95 \% \mathrm{CI}$. $\mathrm{V}_{\mathrm{T}}$ variability was measured from the coefficient of variation. RESULTS: $V_{T}$ distribution over all $f$, effort, and ARDS categories significantly differed across modes $\left(P<.001\right.$, Kruskal-Wallis test). $V_{T}$ was significantly greater with pressure support $(\mathrm{OR} 420 \mathrm{~mL}, 95 \%$ CI 332-527 mL) than with any other mode except for variable pressure support level. Risk for $V_{T}$ to be $>6 \mathrm{~mL} / \mathrm{kg}$ was significantly increased with spontaneous breaths patient-triggered by pressure support (OR 19.36, 95\% CI 12.37-30.65) and significantly reduced in APRV (OR 0.44, 95\% CI 0.26-0.72) and pressure support with guaranteed volume mode. The risk increased with increasing effort and decreasing $f$. Coefficient of variation of $V_{T}$ was greater for low $f$ and volume control-mandatory minute ventilation and pressure control modes. APRV had the greatest within-mode variability. CONCLUSIONS: Risk of $V_{T}>6 \mathrm{~mL} / \mathrm{kg}$ was significantly reduced in APRV and pressure support with guaranteed volume mode. APRV had the highest variability. Pressure support with guaranteed volume could be tested in patients with ARDS. Key words: ARDS; assisted ventilation modes; lung-protective ventilation; pressure-support ventilation; tidal volume; spontaneous breathing; ventilator-induced lung injury. [Respir Care 2017;62(11):1437-1446. (C) 2017 Daedalus Enterprises]
\end{abstract}

\section{Introduction}

In patients with ARDS, it has been shown that setting ventilator tidal volume $\left(\mathrm{V}_{\mathrm{T}}\right)$ to $6 \mathrm{~mL} / \mathrm{kg}$ ideal body weight

\footnotetext{
The authors are affiliated with Réanimation Médicale, Hôpital de la Croix Rousse, Lyon, France. Drs Perinel-Ragey and Guérin are also affiliated with the Université de Lyon, Lyon, France. Dr Guérin is also affiliated with IMRB INSERM 955, Créteil, France.
}

The authors have disclosed no conflicts of interest.

Supplementary material related to this paper is available at http:// www.rcjournal.com.
(IBW) actually accommodates a $4-8-\mathrm{mL} / \mathrm{kg}$ IBW range, which when set at the ventilator can improve survival. ${ }^{1}$ In volume control mode, this goal is easy to achieve when the patient receives sedation and neuromuscular blockade. However, once sedation and paralysis are withdrawn following clinical improvement, spontaneous breathing hap-

Correspondence: Claude Guérin MD PhD, Réanimation Médicale, Hôpital de la Croix Rousse, 69004 Lyon, France. E-mail: claude.guerin@chu-lyon.fr.

DOI: $10.4187 /$ respcare. 05415 


\section{$\mathrm{V}_{\mathrm{T}}$ in Patient-Triggered Mechanical Ventilation in ARDS}

pens, and $\mathrm{V}_{\mathrm{T}}$ becomes more variable as it is not entirely controlled by the ventilator.

In patient-triggered modes of mechanical ventilation, the size of $\mathrm{V}_{\mathrm{T}}$ is determined by the interplay between many factors, which are related to either the patient (lung compliance, lung resistance, effort intensity), the machine (driving pressure, set inspiratory time), or the quality of synchronization between patient effort and mechanical breath. The transition from controlled mechanical ventilation to spontaneous breathing is challenging for the size of $\mathrm{V}_{\mathrm{T}}$. The issue is further complicated by the large number of spontaneous breathing modes with different names and different functionality available across the ICU ventilators. Therefore, issues arise concerning the risk of $\mathrm{V}_{\mathrm{T}}$ falling outside the 4-8-mL/kg IBW range currently recommended. Recently, a large prospective cohort study reported the practice of mechanical ventilation for $\mathrm{ARDS}^{2}$ and found that the mean set $\mathrm{V}_{\mathrm{T}}$ was $7.7 \mathrm{~mL} / \mathrm{kg}$ IBW. We took advantage of this information to carry out a bench study that used data observed in clinical settings over a large number of patients with ARDS.

The main objective of this work was to study the variability of $\mathrm{V}_{\mathrm{T}}$ across different patient-triggered modes of mechanical ventilation in ARDS with different respiratory patterns. In particular, we were looking at the discrepancy across patient-triggered modes of mechanical ventilation from a fixed 6-mL/kg IBW set $\mathrm{V}_{\mathrm{T}}$ in various conditions of respiratory mechanics, breathing frequency (f), and patient effort. The secondary end point was the within-mode variability of $\mathrm{V}_{\mathrm{T}}$. We had the following 4 working hypotheses in mind. (1) In pressure support ventilation (PSV), effort intensity-related $\mathrm{V}_{\mathrm{T}}$ will result in greater $\mathrm{V}_{\mathrm{T}}$ than in other patient-triggered modes because the synchronization between effort and mechanical insufflation is maximal. (2) For patient $f$ lower than set $f$, the increase in $V_{T}$ will be greater than for $f$ higher than set $f$, and this will be further enhanced with stronger effort, higher lung compliance, and PSV. (3) Effort intensity-related $V_{T}$ will result in greater $\mathrm{V}_{\mathrm{T}}$ values in mild ARDS than in moderate or severe categories because lung compliance is greater, and this will be higher in PSV than in other patient-triggered modes. (4) With airway pressure release ventilation (APRV) mode, the magnitude of $\mathrm{V}_{\mathrm{T}}$ will be lower than in PSV, all things being equal, because patient-ventilator asynchrony is more common in APRV.

\section{Methods}

\section{Setup}

Our setup comprised of the following items (see supplementary Fig. 1 at http://www.rcjournal.com): (1) ASL 5000 lung model (IngMar Medical, Pittsburg, Pennsylvania); (2) Evita Infinity V500 (Dräger, Lübeck, Germany)

\section{QUICK LOOK}

\section{Current knowledge}

It is strongly recommended to limit tidal volume $\left(\mathrm{V}_{\mathrm{T}}\right)$ in patients with ARDS. This objective may not be achieved once spontaneous breathing occurs. ICU ventilators have a large number of patient-triggered modes that work differently for a given ventilator and across devices.

\section{What this paper contributes to our knowledge}

In a lung model, pressure support ventilation was associated with a greater risk of high $\mathrm{V}_{\mathrm{T}}$ at low breathing frequency. Airway pressure release ventilation was associated with greater risk of low $\mathrm{V}_{\mathrm{T}}$, with large $\mathrm{V}_{\mathrm{T}}$ variability. Lung protective standards may be violated by ventilator specific operation, despite lung protective settings.

ICU ventilator provided by Dräger France, for the purpose of the present study; (3) heat-and-moisture exchanger (Covidien, Mansfield, Massachusetts), (4) a port for pressure at the airway opening measured proximal to the heat-andmoisture exchanger and connected to a piezoresistive pressure transducer (Gabarith PMSET, Becton Dickinson, Franklin Lakes, New Jersey), and (5) a Fleish 2 pneumotachograph, attached to the port of pressure at the airway opening to measure flow. Flow and pressure at the airway opening signals were connected to an MP150 system (BiopacSystems, Goleta, California). An Evita Infinity V500 ventilator was used in the present study because it is used in our ICU, provides a large selection of patienttriggered ventilation modes, and it is one of the most reliable ICU ventilators for delivering accurate $\mathrm{V}_{\mathrm{T}}{ }^{3}$

\section{ARDS Configuration on the ASL 500 Lung Model}

The Berlin definition ${ }^{4}$ stratifies patients with ARDS into mild, moderate, and severe categories based on the intensity of hypoxemia at PEEP $\geq 5 \mathrm{~cm} \mathrm{H}_{2} \mathrm{O}$. According to the Lung Safe study data, ${ }^{2}$ we adjusted linear lung compliance to 50,40 , and $30 \mathrm{~mL} / \mathrm{cm} \mathrm{H}_{2} \mathrm{O}$ for mild, moderate, and severe ARDS, respectively. Inspiratory resistance was set at 10,15 , and $20 \mathrm{~cm} \mathrm{H}_{2} \mathrm{O} / \mathrm{L} / \mathrm{s}$ and equal to expiratory resistance for each ARDS category.

\section{Patient Effort}

We set the inspiratory effort on the ASL 5000 with a half-sinusoidal profile and a 1-s duration for contraction and post-contraction phase of the respiratory muscles. Two different effort intensities were used: 6 and $12 \mathrm{~cm} \mathrm{H} \mathrm{H}_{2} \mathrm{O}$. 
Table 1. Determination of Breathing Frequencies and Plateau Pressures Used in the Bench Study

\begin{tabular}{|c|c|c|c|}
\hline \multirow{2}{*}{ Study Parameters } & \multicolumn{3}{|c|}{ ARDS Category } \\
\hline & Mild & Moderate & Severe \\
\hline \multicolumn{4}{|l|}{ Lung safe study } \\
\hline Set $\mathrm{f}$ & 17 & 18 & 20 \\
\hline Total f & 20 & 21 & 23 \\
\hline \multicolumn{4}{|l|}{ Present study } \\
\hline Adjusted set $\mathrm{f}$ & 22 & 23 & 25 \\
\hline Adjusted total $\mathrm{f}$ & 26 & 27 & 29 \\
\hline Adjusted low total $\mathrm{f}$ & 13 & 14 & 15 \\
\hline Plateau pressure & 15 & 18 & 23 \\
\hline \multicolumn{4}{|c|}{$\begin{array}{l}\text { Breathing frequencies are expressed as breaths } / \mathrm{min} \text { and plateau pressures as } \mathrm{cm}_{2} \mathrm{O} \text {. Adjusted } \\
\text { breathing frequencies are for tidal volume of } 6 \mathrm{~mL} / \mathrm{kg} \text { of predicted body weight. The low breathing } \\
\text { frequencies are } 50 \% \text { of the value found in the Lung Safe study. Plateau pressures were } \\
\text { determined in volume-controlled ventilation using a } 390-\mathrm{mL} \text { tidal volume, inspiratory time of } \\
0.8 \mathrm{~s} \text {, flow of } 60 \mathrm{~L} / \mathrm{min} \text {, and positive end-expiratory pressure of } 7,8 \text {, and } 10 \mathrm{~cm} \mathrm{H}_{2} \mathrm{O} \text { for mild, } \\
\text { moderate, and severe ARDS, respectively. } \\
\mathrm{f}=\text { breathing frequency }\end{array}$} \\
\hline
\end{tabular}

\section{Ventilator Settings}

From the average patient's height of $1.68 \mathrm{~m}$ in the Lung Safe study, ${ }^{2}$ we computed that IBW was $64 \mathrm{~kg}$, and hence our 6-mL/kg IBW $\mathrm{V}_{\mathrm{T}}$ target, regardless of sex, was $390 \mathrm{~mL}$. In the Lung Safe study, the set $\mathrm{V}_{\mathrm{T}}$ averaged 7.8, 7.6, and $7.5 \mathrm{~mL} / \mathrm{kg}$ IBW (ie, 130,127 , and $125 \%$ of the $6-\mathrm{mL} / \mathrm{kg}$ IBW in mild, moderate, and severe ARDS, respectively). We applied this percentage point to both the total and set $\mathrm{f}$ in the Lung Safe study to compute adjusted total and set $\mathrm{f}$ in the present study to maintain an equivalent minute ventilation (Table 1). Furthermore, we applied both total and set $\mathrm{f}$ amounting to $50 \%$ of previous $\mathrm{f}$ values to mimic the situation that occurs after interruption of paralysis and sedation when respiratory centers are still depressed.

We used these settings in volume control mode in a preliminary bench study to determine the amount of pressure support to be applied in mild, moderate, and severe ARDS (Table 1).

\section{Ventilator Modes Set on the ICU Ventilator}

We investigated 13 ventilation modes. These modes fell into 3 main categories: (variable imposed volume mode, pressure control ventilation and proxy modes, and spontaneous breathing modes), which are described in detail in supplementary Table 1 . The settings applied in each mode are shown in Table 2.

In each mode, the preset limits of alarms on $\mathrm{V}_{\mathrm{T}}$ and minute ventilation were those set by default, namely $20-$ $50 \%$ and $50-99 \%$ of the corresponding set values. The upper-airway pressure alarm was set at its maximal value, $100 \mathrm{~cm} \mathrm{H}_{2} \mathrm{O}$.

\section{Protocol}

The study was performed on a single day in a dedicated place in our ICU for ventilator bench testing, at room air and temperature. A double limb standard ventilator circuit (Intersurgical Wokingham, Berkshire, United Kingdom) was used. The ventilator attached to the circuit and the heat-and-moisture exchanger passed the steps of the checking process immediately before the protocol for leaks and circuit compliance assessment. $\mathrm{F}_{\mathrm{IO}_{2}}$ was 0.21 , and the humidifier was omitted. The pressure transducer for pressure at the airway opening measurement and Fleish 2 pneumotachograph were calibrated before the experiment. The 13 modes were run in the order provided in Table 2 for each condition. For each mode and each ARDS configuration, $2 \mathrm{f}$ values (Table 1) and both effort levels were applied, resulting in 13 modes $\times 3$ ARDS configurations $\times 2 \mathrm{f} \times 2$ efforts (ie, 156 single conditions). The recordings were performed at $200 \mathrm{~Hz}$ for $3 \mathrm{~min}$ by using Acqknowledge 4.4.0 (BiopacSystems).

\section{Data Analysis}

The last 30 breaths of each single condition were manually analyzed. Therefore, a total of 4,680 breaths were analyzed by an investigator (SPR). Expired $\mathrm{V}_{\mathrm{T}}$ was obtained by digital integration of the flow signal. The analysis was made by using Acqknowledge 4.4.0.

The primary end point was the distribution of $\mathrm{V}_{\mathrm{T}}$ across ventilator modes. The secondary end points were the probability for ventilator modes to depart from the $4-8-\mathrm{mL} / \mathrm{kg}$ IBW window and the coefficient of variation of $\mathrm{V}_{\mathrm{T}}$.

Results are reported as median (interquartile range). The normal distribution of $\mathrm{V}_{\mathrm{T}}$ was checked by using the Shapiro-Wilkes test. The statistical analysis strategy was performed as follows. We first used a linear mixed-effects model to describe the relationship between $\mathrm{V}_{\mathrm{T}}$ (the response variable) and ventilator modes, f, and effort (the covariates) over all ARDS categories. Breathing frequency and effort were treated as 2-level categorical variables. The rationale for merging all of the ARDS categories was that the ventilator settings were selected after taking into account the characteristics of ARDS. In case of interaction between the covariates, we planned to perform a series of non-parametric or parametric analyses of variance to test the effect of ventilator mode on $\mathrm{V}_{\mathrm{T}}$ at each $\mathrm{f}$ and effort. That means that we planned to perform Kruskal-Wallis non-parametric or one-way analysis of variance, depending on the distribution of $\mathrm{V}_{\mathrm{T}}$. For each test, we planned post hoc comparisons with PSV without guaranteed $\mathrm{V}_{\mathrm{T}}$, used as the control, by using the Dunn test or Dunnett test, respectively. PSV was used as a control because it is the 
$\mathrm{V}_{\mathrm{T}}$ in Patient-Triggered Mechanical Ventilation in ARDS

Table 2. Ventilator Settings Across Modes Used in the Bench Study for Mild, Moderate, and Severe ARDS

\begin{tabular}{|c|c|c|c|c|c|c|c|c|c|}
\hline Mode & $\begin{array}{c}\text { 6-mL/kg } \\
\text { IBW Target } \\
\mathrm{V}_{\mathrm{T}}(\mathrm{mL})\end{array}$ & $\begin{array}{l}\mathrm{T}_{\mathrm{I}} \\
(\mathrm{s})\end{array}$ & $\begin{array}{l}\text { Maximum } \\
\mathrm{T}_{\mathrm{I}}(\mathrm{s})\end{array}$ & $\begin{array}{c}\mathrm{f} \\
\text { (breaths/min) }\end{array}$ & $\begin{array}{c}\text { Set } \mathrm{P}_{\mathrm{I}} \\
\left(\mathrm{cm} \mathrm{H} \mathrm{H}_{2} \mathrm{O}\right)\end{array}$ & $\begin{array}{c}\mathrm{PS} \\
\left(\mathrm{cm} \mathrm{H} \mathrm{H}_{2} \mathrm{O}\right)\end{array}$ & $\begin{array}{c}\text { PEEP } \\
\left(\mathrm{cm} \mathrm{H}_{2} \mathrm{O}\right)\end{array}$ & $\begin{array}{c}\text { Flow } \\
\text { (L/min) }\end{array}$ & $\begin{array}{l}\text { Variable } \\
\text { PS }(\%)\end{array}$ \\
\hline VCV-MMV-PSVX* & 390 & 0.8 & NA & $22 * / 23 \dagger / 25 \ddagger$ & NA & $0 / 8 * / 9 \dagger / 13 \ddagger$ & $7 * / 8+/ 10+$ & 60 & NA \\
\hline VCV-MMV-PSVX-AF & 390 & 0.8 & NA & $22 * / 23 \dagger / 25 \ddagger$ & NA & $0 / 8 * / 9 \dagger / 13 \ddagger$ & $7 * / 8+/ 10 \ddagger$ & $\mathrm{AF}$ & NA \\
\hline & NA & NA & NA & $22 * / 23 \dagger / 25 \ddagger$ & NA & NA & $7 * / 8 \dagger / 10 \ddagger$ & NA & NA \\
\hline PCV-BPAP & NA & 0.8 & NA & $22 * / 23 \dagger / 25 \ddagger$ & $15 * / 17 \dagger / 23 \ddagger$ & $8 * / 9 \dagger / 13 \neq$ & $7 * / 8 \dagger / 10 \ddagger$ & NA & NA \\
\hline APRV & NA & NA & $\begin{array}{c}\mathrm{T} \text { high 1; T low } \\
1.7 / 1.6 / 1.4\end{array}$ & NA & $15 * / 17 \dagger / 23 \ddagger$ & NA & $7 * / 8+/ 10 \ddagger$ & NA & NA \\
\hline PCV-PSV & NA & NA & NA & $22 * / 23 \dagger / 25 \ddagger$ & $15 * / 17 \dagger / 23 \ddagger$ & NA & $7 * / 8 \dagger / 10 \ddagger$ & NA & NA \\
\hline PCV-PSV-GTV & $390(\mathrm{G})$ & 0.8 & NA & $22 * / 23 \dagger / 25 \ddagger$ & $15 * / 17 \dagger / 23 \ddagger$ & NA & $7 * / 8 \dagger / 10+$ & NA & NA \\
\hline PSV & NA & NA & No & NA & NA & $8 * / 9 \dagger / 13 \neq$ & $7 * / 8 \dagger / 10$ \% & NA & No \\
\hline PSV-GTV & $390(\mathrm{G})$ & NA & No & NA & NA & NA & $7 * / 8+/ 10 \ddagger$ & NA & No \\
\hline PSV-var40/60/80 & NA & NA & No & NA & NA & $8 * / 9 \dagger / 13 \ddagger$ & $7 * / 8+/ 10 \ddagger$ & NA & $40 / 60 / 80$ \\
\hline $\begin{array}{l}\text { Maximal slope for pressure rise } \\
* \text { Mild ARDS. } \\
\text { † Moderate ARDS. } \\
\text { ‡ Severe ARDS. } \\
\text { PBW = predicted body weight } \\
\mathrm{V}_{\mathrm{T}}=\text { tidal volume } \\
\mathrm{T}_{\mathrm{I}}=\text { inspiratory time } \\
\mathrm{f}=\text { breathing frequency } \\
\mathrm{P}_{\mathrm{I}}=\text { inspiratory pressure } \\
\mathrm{PS}=\text { pressure support } \\
\mathrm{VCV}=\text { volume control ventilat } \\
\mathrm{MMV}=\text { mandatory minute ven } \\
\mathrm{PSVX}=\text { pressure support ventil } \\
\mathrm{NA}=\text { not applicable } \\
\mathrm{AF}=\text { Autoflow } \\
\mathrm{PCV}=\text { pressure control ventilat } \\
\mathrm{BPAP}=\text { biphasic positive airwa } \\
\text { APRV = airway pressure releas } \\
\mathrm{PSV}=\text { pressure support ventilat } \\
\mathrm{GTV}=\text { guaranteed tidal volume } \\
\mathrm{G}=\text { guaranteed } \\
\text { var = variable pressure support }\end{array}$ & $\begin{array}{l}\text { xcept for no slope } \\
\text { ation } \\
\text { ion with a support } \\
\text { pressure } \\
\text { ventilation } \\
\text { n }\end{array}$ & iven in $\mathrm{t}$ & PS column & & & & & & \\
\hline
\end{tabular}

most widely used patient-triggered ventilation mode. 5 Second, the distribution of $\mathrm{V}_{\mathrm{T}}$ was compared between modes across each ARDS category for all $\mathrm{f}$ and effort by using either the Friedman test or 2-factor analysis of variance, depending on the distribution of $\mathrm{V}_{\mathrm{T}}$. We, however, also planned sensitivity analyses in each ARDS category. Sensitivity analyses were performed with the same strategy for each ARDS category as the one we used for ARDS as a whole.

The probability of $\mathrm{V}_{\mathrm{T}}>6$ or $8 \mathrm{~mL} / \mathrm{kg}$ IBW or $<6$ or $4 \mathrm{~mL} / \mathrm{kg}$ IBW across ventilator modes was computed according to a binary logistic regression for each $\mathrm{V}_{\mathrm{T}}$ and effort over all ARDS categories. Results of this analysis are reported as odd ratios with $95 \% \mathrm{CI}$.

Finally, the coefficient of variation of $\mathrm{V}_{\mathrm{T}}$ was computed as the ratio of SD to its mean for each single condition. The distribution of $\mathrm{V}_{\mathrm{T}}$ was described by using the gaussian Kernel density plots. $P<.05$ was considered as the statistically significant threshold. Statistical analysis was performed by using R 3.2.0 (R Foundation for Statistical Computing, Vienna, Austria).

\section{Results}

$\mathrm{V}_{\mathrm{T}}$ did not follow the normal distribution; hence, nonparametric tests were used throughout.

\section{$\mathbf{V}_{\mathrm{T}}$ Across Modes}

The distribution of $\mathrm{V}_{\mathrm{T}}$ over all $\mathrm{f}$, effort, and ARDS categories significantly differed across modes (Fig. 1) $(P<.001$, Kruskal-Wallis test $) . \mathrm{V}_{\mathrm{T}}$ was significantly greater with PSV than with any other mode except for the 3 variable pressure support level modes (Fig. 1).

\section{$\mathrm{V}_{\mathrm{T}}$ Across Modes According to $\mathrm{f}$ and Effort}

The mixed-effects model found that modes, $\mathrm{f}$, and effort intensity were significantly associated with $\mathrm{V}_{\mathrm{T}}$ with a significant interaction between them. Therefore, we split the analysis into 4 subgroups determined by the combination of $\mathrm{f}$ and effort intensity. The distribution of $\mathrm{V}_{\mathrm{T}}$ with modes for the different $\mathrm{f}$ and efforts, for all ARDS categories, is 


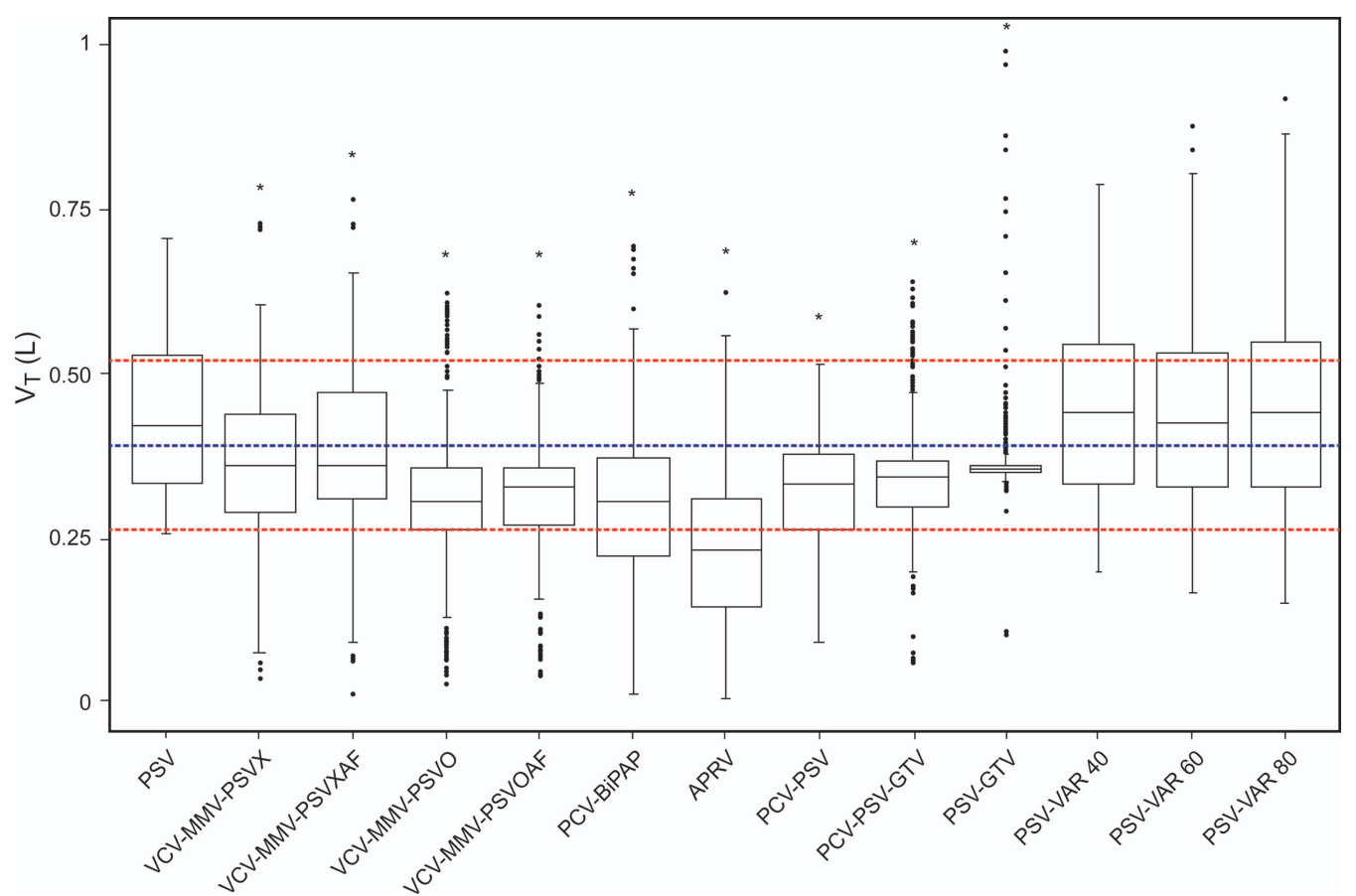

Fig. 1. Box-and-whisker plots of tidal volumes across ventilator modes over all efforts, breathing frequencies, and ARDS categories. The upper and lower red lines and center blue line represent 4-, 8-, and 6-mL/kg ideal body weight tidal volume, respectively. Boxes represent first and third quartiles, center lines denote the median, whiskers represent maximal values, and points are outliers. PSV = pressure support ventilation, $\mathrm{VCV}=$ volume control ventilation, $\mathrm{MMV}=$ mandatory minute ventilation, $\mathrm{AF}=$ Autoflow, $\mathrm{PCV}=$ pressure control ventilation, $\mathrm{BiPAP}=$ biphasic positive airway pressure, APRV = airway pressure release ventilation, GTV $=$ guaranteed tidal volume, $\mathrm{VAR}=$ variable. Individual points are outliers. ${ }^{*}, P<.001$ versus PSV.

shown in Figure 2, and it differed significantly across modes $(P<.001$, Kruskal-Wallis test). For both low $\mathrm{f}$ and effort, $\mathrm{V}_{\mathrm{T}}$ was significantly greater with PSV than with any other mode except for the 3 modes accommodating a variable pressure support level (Fig. 2). For the high $f$ and low effort $\left(6 \mathrm{~cm} \mathrm{H}_{2} \mathrm{O}\right)$, only APRV and PSV-guaranteed $\mathrm{V}_{\mathrm{T}}$ showed a significantly lower $\mathrm{V}_{\mathrm{T}}$ than PSV. Lastly, for both high $\mathrm{f}$ and effort $\left(12 \mathrm{~cm} \mathrm{H}_{2} \mathrm{O}\right)$, volume control ventilation (VCV)-mandatory minute ventilation with no pressure support modes, APRV, pressure control ventilationPSV-guaranteed $V_{T}$, and PSV-guaranteed $V_{T}$ had significantly lower $\mathrm{V}_{\mathrm{T}}$ than PSV.

\section{$\mathrm{V}_{\mathrm{T}}$ Across Modes According to ARDS Categories}

The distribution of $\mathrm{V}_{\mathrm{T}}$ across modes over all $\mathrm{f}$ and effort for mild, moderate, and severe ARDS is shown in Figure 3. Both modes and ARDS categories significantly impacted $\mathrm{V}_{\mathrm{T}}$, but significant interaction between them was present $(P<.001$ for mode, ARDS category, and their interaction; Friedman test), which precludes the assessment of each of them.

The distribution of $\mathrm{V}_{\mathrm{T}}$ across modes over each $\mathrm{f}$ and effort for the 3 categories of ARDS is shown in supplemental Figure 2. As described above, modes and ARDS categories had a significant impact on $\mathrm{V}_{\mathrm{T}}$, but interaction between them was significant.

\section{Probability of $V_{T}$ Falling Outside the 4-8-mL/kg IBW Range}

The risk of $\mathrm{V}_{\mathrm{T}}>6 \mathrm{~mL} / \mathrm{kg}$ IBW significantly increased as soon as breaths were patient-triggered by PSV modes and significantly went down in APRV and PSV-guaranteed $\mathrm{V}_{\mathrm{T}}$ modes (Fig. 4). This risk increased with greater effort and lower f (Fig. 4).

The risk of $\mathrm{V}_{\mathrm{T}}>8 \mathrm{~mL} / \mathrm{kg}$ IBW significantly increased with the PSV modes without guaranteed $\mathrm{V}_{\mathrm{T}}$ and with the effort intensity (supplemental Fig. 3). On the other hand, this risk was significantly lower for pressure control ventilation modes, VCV-mandatory minute ventilation modes without pressure support, PSV-guaranteed $\mathrm{V}_{\mathrm{T}}$, and higher f. The risk of $V_{T}<4 \mathrm{~mL} / \mathrm{kg}$ IBW was significantly increased for pressure control ventilation modes except if the guaranteed $\mathrm{V}_{\mathrm{T}}$ option was activated and for VCVmandatory minute ventilation modes without pressure support but significantly decreased for all of the PSV modes. The effect of greater effort and $\mathrm{f}$ was not significant for $\mathrm{V}_{\mathrm{T}}$ risk $<4 \mathrm{~mL} / \mathrm{kg}$ IBW. 

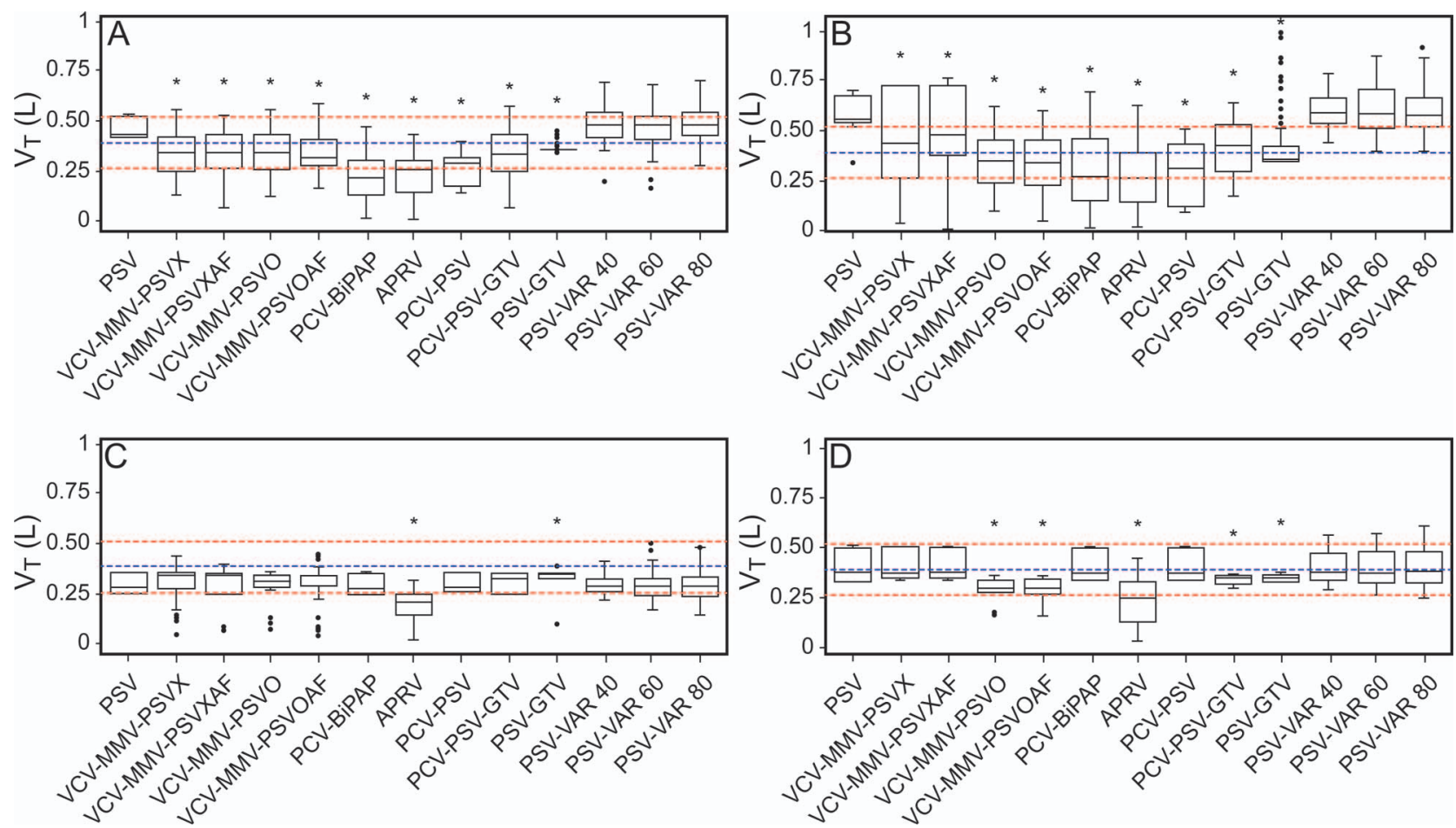

Fig. 2. Box-and-whisker plots of tidal volumes $\left(V_{T}\right)$ across ventilator modes over all ARDS categories, $V_{T}$ for each effort, and breathing frequency (f). The upper and lower red lines and center blue lines represent 4-, 8-, and 6-mL/kg ideal body weight tidal volume, respectively. A: Low $f$ and low effort. B: Low $f$ and high effort. C: High $f$ and low effort. D: High $f$ and high effort. Boxes represent first and third quartiles, center lines denote the median, whiskers represent maximal values, and points are outliers. PSV $=$ pressure support ventilation, VCV $=$ volume control ventilation, $\mathrm{MMV}=$ mandatory minute ventilation, $\mathrm{AF}=$ Autoflow, $\mathrm{PCV}=$ pressure control ventilation, BiPAP $=$ biphasic positive airway pressure, APRV = airway pressure release ventilation, GTV = guaranteed tidal volume, VAR $=$ variable. Individual points are outliers. ${ }^{*}, P<.01$ versus PSV.

\section{Coefficients of Variation}

The coefficients of variation across ventilator modes according to $f$ and effort for all ARDS categories are shown in Figure 5. The coefficients of variation were greater for low $\mathrm{f}$ and for $\mathrm{VCV}$-mandatory minute ventilation and pressure control modes, reaching $>25 \%$ for all of these conditions. APRV had the greatest variability, exhibiting a very high coefficient of variation, even at high $\mathrm{f}$. Effort and ARDS categories had a low impact on the coefficient of variation. The density plots of $\mathrm{V}_{\mathrm{T}}$ exhibited different distribution patterns (supplemental Fig. 4).

\section{Discussion}

The main findings of the present study were that (1) as expected, $\mathrm{V}_{\mathrm{T}}$ significantly differed across ventilator modes, $\mathrm{f}$, effort, and ARDS categories with significant interaction between these factors; (2) $\mathrm{V}_{\mathrm{T}}$ was significantly greater with PSV than with any other mode except for those accommodating a variable pressure support level; (3) low f showed the same significant differences across modes as in the global analysis, but the effect was more homoge- neous for high f; (4) APRV and PSV-guaranteed $V_{T}$ showed significant lower $\mathrm{V}_{\mathrm{T}}$ in all of the conditions; (5) the risk of $\mathrm{V}_{\mathrm{T}}>6 \mathrm{~mL} / \mathrm{kg}$ IBW was significantly increased with PSV modes and with the effort intensity and significantly reduced with high $\mathrm{f}$ and in APRV and PSV-guaranteed $\mathrm{V}_{\mathrm{T}}$; and (6) the coefficient of variation was greater at low $f$ and with APRV.

To our knowledge, this is the first study comparing all of the available patient-triggered modes in the V500 Infinity ICU ventilator on the bench in conditions that realistically mimicked ARDS. The accuracy of the latest generation of ventilators to deliver the chosen parameters was studied by Garnier et al. ${ }^{3}$ This study showed that the V500 Infinity ICU ventilator was one of the most reliable available. Specifically, the delivered $\mathrm{V}_{\mathrm{T}}$ fell within the $10 \%$ range of variability for the $\mathrm{V}_{\mathrm{T}}$ set. Therefore, in the context of the present study, the selection of this ventilator is judicious, and the accuracy of $\mathrm{V}_{\mathrm{T}}$ delivery from this ventilator makes the assessment of $\mathrm{V}_{\mathrm{T}}$ a relevant primary end point. The risk of high $\mathrm{V}_{\mathrm{T}}$ with patient-triggered modes was pointed out in a bench study on 4 ICU ventilators, and more specifically, the Autoflow option on the Evita XL ventilator was found to increase the $\mathrm{V}_{\mathrm{T}}$ variability. ${ }^{6} \mathrm{How}-$ 


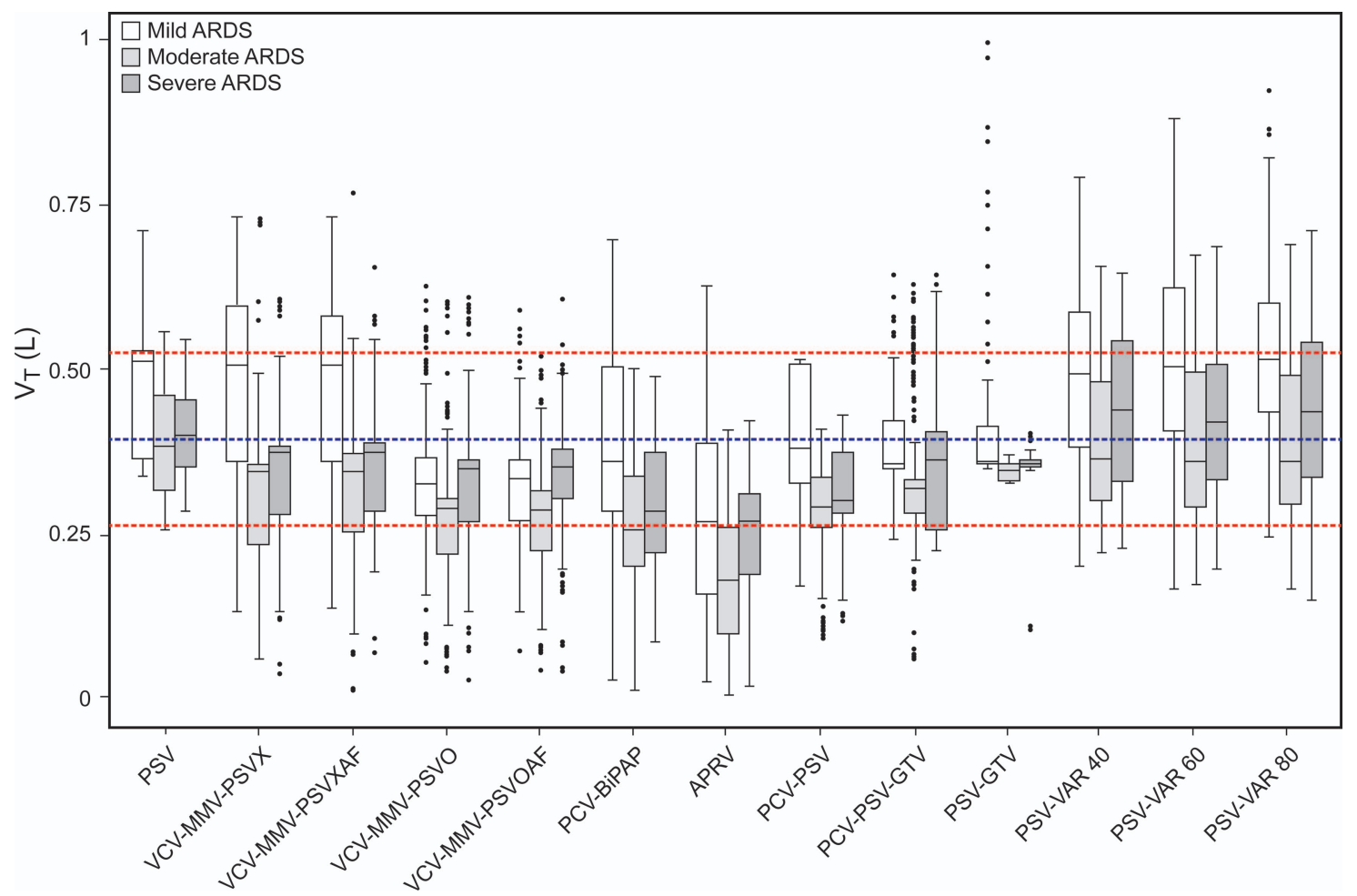

Fig. 3. Box-and-whisker plots of tidal volumes across ventilator modes according to the ARDS type (mild, moderate, or severe) for each effort and breathing frequency. The upper and lower red lines and center blue line represent 4-, 8-, and 6-mL/kg ideal body weight tidal volume, respectively. Boxes represent first and third quartiles, center lines denote the median, whiskers represent maximal values, and points are outliers. PSV $=$ pressure support ventilation, $\mathrm{VCV}=$ volume control ventilation, $\mathrm{MMV}=$ mandatory minute ventilation, $\mathrm{AF}=$ Autoflow, PCV = pressure control ventilation, BiPAP = biphasic positive airway pressure, APRV = airway pressure release ventilation, GTV $=$ guaranteed tidal volume, VAR $=$ variable. Ventilator mode effect, ARDS category effect, and ventilator $\times$ ARDS category effect are all $P<.001$.

ever, each company develops specific modes, so patienttriggered ventilation modes are numerous, and each one of them is almost unique. Furthermore, the comparability of patient-triggered modes is difficult to assess within and across brands.

Once spontaneous breathing happens during mechanical ventilation in ICU patients, and hence patient-triggered modes are used, the risk of ventilator-induced lung injury has been suggested to be greater than during lung-protective controlled mechanical ventilation. ${ }^{7}$ This is due to the fact that once pressure-targeted modes are used, the size of $\mathrm{V}_{\mathrm{T}}$ depends on the patient's effort, which depends on the intensity of drive and respiratory muscle strength and hence is difficult for the clinician to reduce apart from sedation resumption.

Our first hypothesis was that in PSV, the effort intensity-related $\mathrm{V}_{\mathrm{T}}$ will result in greater $\mathrm{V}_{\mathrm{T}}$ than in other patient-triggered modes because the synchronization between effort and mechanical insufflation is maximal. Present data confirmed this hypothesis, which reflects some clinical experience. ${ }^{8}$ The impact of increasing effort, which was clear at low $\mathrm{f}$, was less consistent at high $\mathrm{f}$ in our study. This finding may be due to the interaction between $f$ and effort. When spontaneous breathing is superimposed onto pressure-targeted not time-cycled modes, as long as $\mathrm{f}$ increases, $\mathrm{V}_{\mathrm{T}}$ decreases because inspiratory time decreases. With increasing $f$, and other parameters being equal, $V_{T}$ should decrease.

The second hypothesis was that for the patient's f lower than the set $\mathrm{f}, \mathrm{V}_{\mathrm{T}}$ will increase more than for the patient's $\mathrm{f}$ higher than the set $\mathrm{f}$, and this will be further enhanced with stronger effort, higher lung compliance, and PSV. Indeed, as shown in Figure 2, $\mathrm{V}_{\mathrm{T}}$ is higher at low $\mathrm{f}$, and this is further extended at the higher effort of $12 \mathrm{~cm} \mathrm{H}_{2} \mathrm{O}$. The impact of ventilation mode at low $\mathrm{f}$ was also enhanced in PSV modes as compared with the others, except if the variable PSV option was activated. However, the impact of this mode is less significant at high $\mathrm{f}$. The probable explanation is the opposite effect on the magnitude of $\mathrm{V}_{\mathrm{T}}$ of $f$ and effort increase. It can be assumed that once sedation and paralysis are withdrawn when spontaneous breathing happens but is not completely efficient, f remains low with high efforts because of residual sedation. Therefore, this transient stage should put the patient at high risk of greater variability of $\mathrm{V}_{\mathrm{T}}$. Another explanation for $\mathrm{V}_{\mathrm{T}}$ variability could be the change in end-expiratory 


\section{$\mathrm{V}_{\mathrm{T}}$ in Patient-Triggered Mechanical Ventilation in ARDS}

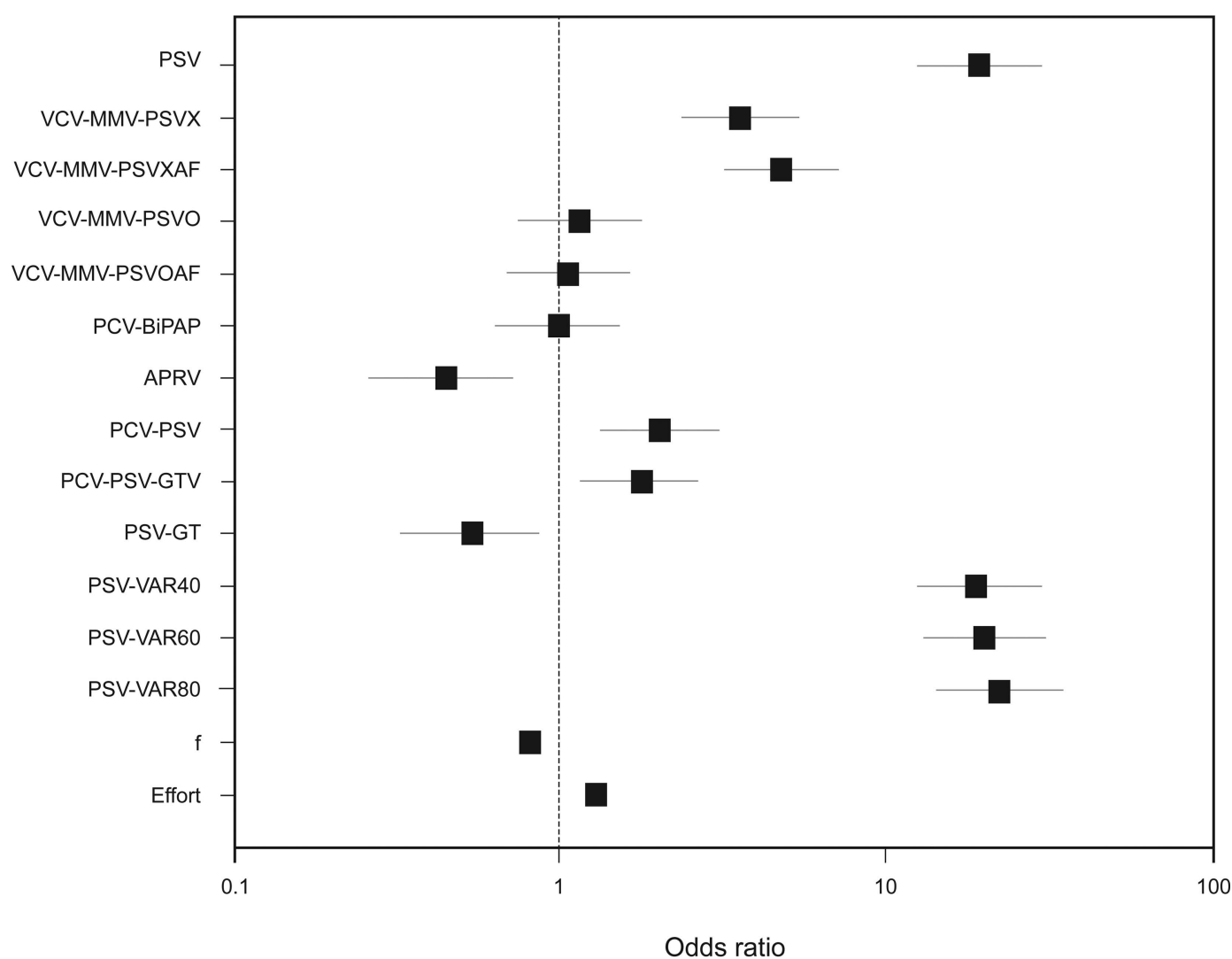

Fig. 4. Forest plot for tidal volume $>6 \mathrm{~mL} / \mathrm{kg}$ ideal body weight across ventilator modes. $\mathrm{V}_{\mathrm{T}}=$ tidal volume, $\mathrm{PSV}=$ pressure support ventilation, $\mathrm{VCV}=$ volume control ventilation, $\mathrm{MMV}=$ mandatory minute ventilation, $\mathrm{AF}=$ Autoflow, $\mathrm{PCV}=$ pressure control ventilation, $\mathrm{BiPAP}=$ biphasic positive airway pressure, $\mathrm{APRV}=$ airway pressure release ventilation, $\mathrm{GTV}=$ guaranteed tidal volume, $\mathrm{VAR}=\mathrm{variable}$, $f=$ breathing frequency.

lung volume. However, we did not assess it in the present study.

Our third hypothesis was that effort intensity-related $\mathrm{V}_{\mathrm{T}}$ will result in greater $\mathrm{V}_{\mathrm{T}}$ values in mild ARDS than in the moderate or severe categories because lung compliance is greater, and this will be higher in PSV than in other patient-triggered modes. The impact of ARDS category was not so strong, as can be seen in Figure 3. One possible explanation could be that the level of pressure support was determined in accordance with ARDS mechanical characteristics and hence matched the lung compliance of each ARDS category. However, this is not the only explanation, because this hypothesis seems true for moderate as compared with mild ARDS but not for severe ARDS. Last, there is a significant interaction between ARDS category and ventilator mode, which means that statistical analysis cannot assess the effect of each main factor on $\mathrm{V}_{\mathrm{T}}$.

The last hypothesis was that in APRV, the magnitude of $\mathrm{V}_{\mathrm{T}}$ would be lower than in PSV, everything else being equal, because synchronization is less in the former mode. This is clearly confirmed by our results, with significantly lower $\mathrm{V}_{\mathrm{T}}$ in all of the conditions and a 10 times greater chance to reach $\mathrm{V}_{\mathrm{T}}<4 \mathrm{~mL} / \mathrm{kg}$ IBW. This would make
APRV an interesting mode to limit the risk of overinflation. However, the coefficient of variation of $\mathrm{V}_{\mathrm{T}}$ was extremely high for APRV. This means that using this specific mode, even if the risk of overinflation is probably decreased, there is concomitant risk of atelectrauma, making APRV a double-edged sword ventilator strategy. We did not assess spontaneous and mandatory $\mathrm{V}_{\mathrm{T}}$ separately. Indeed, spontaneous $\mathrm{V}_{\mathrm{T}}$ was so low that it did not significantly impact the results of $\mathrm{V}_{\mathrm{T}}$ and was furthermore included into the whole expired $\mathrm{V}_{\mathrm{T}}$ that we measured.

\section{Limitations and Strengths}

The strengths of the present study are that (1) it systematically tested ventilator modes in strict experimental conditions, (2) a large number of patient-triggered ventilator modes of the same ICU ventilator were tested, and (3) realistic values of lung compliance and $f$ were used because these were taken from observed clinical data pertaining to the current management of ARDS throughout the world and obtained over a large sample size. The first limitation of this study is its bench nature. Obviously, 

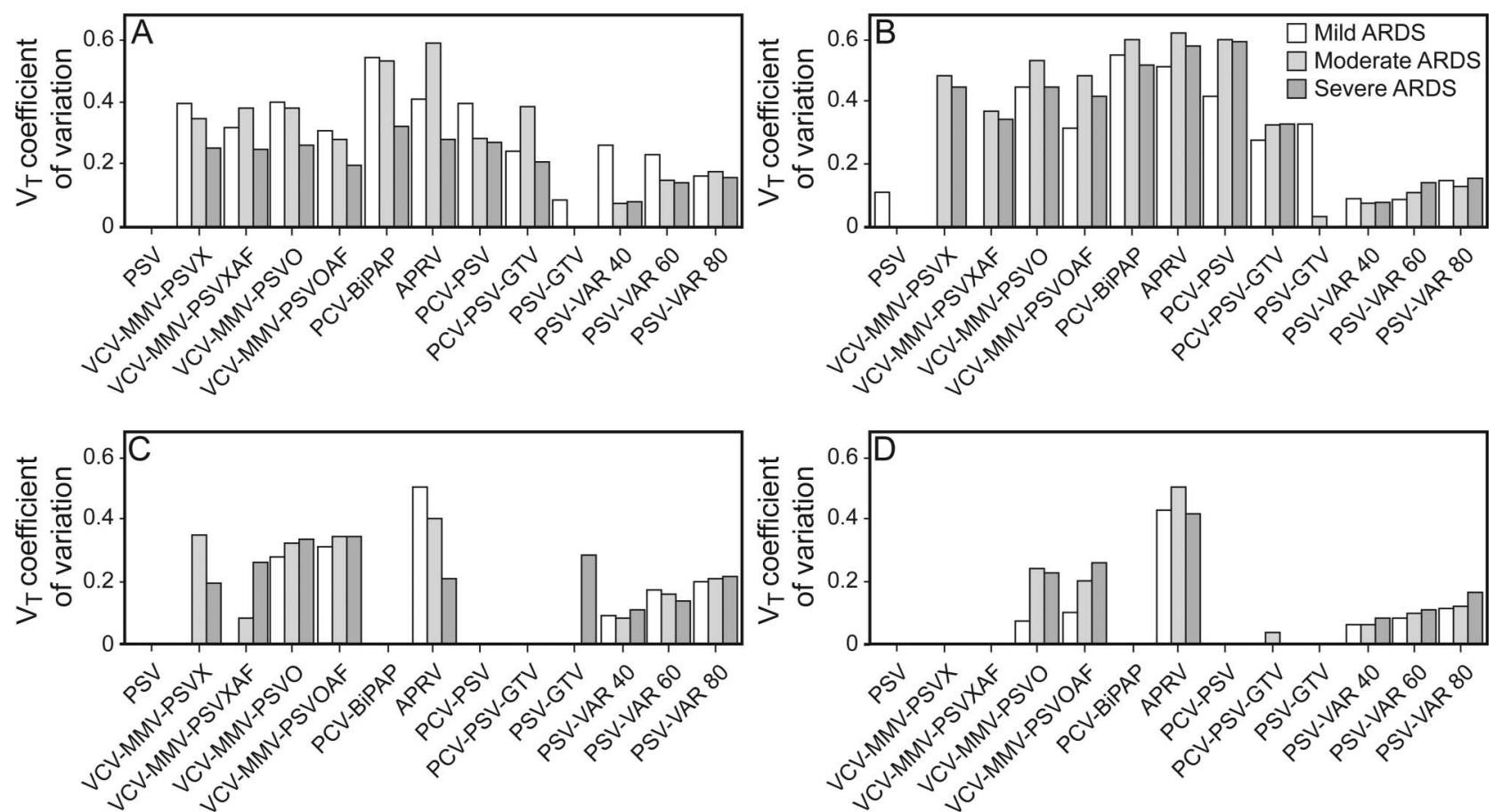

Fig. 5. Coefficients of variation across ventilation modes and ARDS categories for each combination of effort and breathing frequency. A: Low $f$ and low effort. B: Low $f$ and high effort. C: High $f$ and low effort. D: High $f$ and high effort. When any symbol is visible, the coefficient of variation is nil. $\mathrm{V}_{\mathrm{T}}=$ tidal volume, $\mathrm{PSV}=$ pressure support ventilation, $\mathrm{VCV}=$ volume control ventilation, $\mathrm{MMV}=$ mandatory minute ventilation, $\mathrm{AF}=$ Autoflow, $\mathrm{PCV}=$ pressure control ventilation, $\mathrm{BiPAP}=$ biphasic positive airway pressure, $\mathrm{APRV}=$ airway pressure release ventilation, GTV = guaranteed tidal volume, $\mathrm{VAR}=$ variable.

bench conditions are not equivalent to patients in whom efforts can be highly variable, as are lung compliance and resistance from breath to breath. Further limitations are that (1) the present results cannot be extrapolated to specific patient-triggered modes available in other ICU ventilators; (2) asynchronies between patient and ventilator were not assessed; (3) levels of patient effort were arbitrarily chosen; (4) linear compliance was used, which is a realistic assumption in the $\mathrm{V}_{\mathrm{T}}$ range and makes the comparisons between conditions more relevant; and (5) no endotracheal tube was used in order to avoid leaks and resistance variability.

\section{Clinical Implications}

Clinicians must be aware of the risk of using patienttriggered modes of mechanical ventilation regarding the size of $\mathrm{V}_{\mathrm{T}}$ and its variability across the various modes available in ICU ventilators. It should be mentioned that an animal study ${ }^{9}$ found that spontaneous breathing was more harmful to the lung in cases of severe rather than mild acute lung injury for the same effort intensity. This risk was also described in a volume control patient-triggered mode. ${ }^{10}$ The risk of overinflation from using the modes with full synchronization between patient effort and mechanical breath delivery was pointed out, and it was found that APRV resulted in low $\mathrm{V}_{\mathrm{T}}$ and a high variability. ${ }^{11}$ It should be mentioned that although $\mathrm{V}_{\mathrm{T}}$ would not be greatly increased in patient-triggered mechanical breaths, lung injury may occur in the non-dependent regions due to the pendelluft phenomenon during the same inspiration. ${ }^{12}$

PSV, which is the second most frequently used mode of mechanical ventilation after VCV, is also the one with the greater risk of $\mathrm{V}_{\mathrm{T}}>6 \mathrm{~mL} / \mathrm{kg} \mathrm{IBW}$, and the risk is even more important than with the other modes tested obtaining $\mathrm{V}_{\mathrm{T}}>8 \mathrm{~mL} / \mathrm{kg}$ IBW. Spontaneous effort can recruit part of the lungs but may cause occult pendelluft during the same inspiration..$^{12}$ Experimental studies ${ }^{10}$ suggested that ventilator-induced lung injury may result from spontaneous patient-triggered breaths. Although direct and definitive evidence for ventilator-induced lung injury in the recovering patient does not really exist in the clinical realm, these experimental data and experts' opinion pointed this out. This finding suggests that the new modes tested in the present study may be of interest for patients with ARDS. The observed increasing $\mathrm{V}_{\mathrm{T}}$ with low $\mathrm{f}$ and high efforts pertains to the clinical situation of sedation and is in line with the recommendation to limit the duration of sedation in ICU patients. ${ }^{13}$ APRV and PSV-guaranteed $V_{T}$ showed significantly lower $\mathrm{V}_{\mathrm{T}}$ in all of the conditions, but the high variability of APRV could be iatrogenic too. Consequently, 


\section{$\mathrm{V}_{\mathrm{T}}$ IN Patient-Triggered Mechanical Ventilation in ARDS}

further studies on PSV-guaranteed $\mathrm{V}_{\mathrm{T}}$ in the clinical setting could be discussed. Proportional modes of ventilation are attractive options to minimize the risk of overinflation resulting from high effort with pressure-targeted modes. It was shown that patients receiving controlled ventilation with lung-protective settings and then proportional patienttriggered ventilation may keep the control of the driving pressure. ${ }^{14}$ When driving pressure was high in controlled ventilation, it decreased in proportional patient-triggered ventilation, and the opposite was true when it was low. Finally, to better control the patient's effort, it has been suggested to use a low dose of neuromuscular blockade in spontaneously breathing patients under sedation. ${ }^{15}$

\section{Conclusions}

The ventilation mode had an important impact on $\mathrm{V}_{\mathrm{T}}$ in this study. The risk of $\mathrm{V}_{\mathrm{T}}>6 \mathrm{~mL} / \mathrm{kg}$ IBW was significantly reduced in APRV and PSV with volume-guaranteed mode. APRV had the highest variability. PSV with guaranteed volume could be tested in patients with ARDS.

\section{ACKNOWLEDGMENTS}

We thank Patrice Loconte (Dräger France) for providing the V500 Infinity ICU ventilator.

\section{REFERENCES}

1. Acute Respiratory Distress Syndrome Network, Brower RG, Matthay MA, Morris A, Schoenfeld D, Thompson BT, Wheeler A. Ventilation with lower tidal volumes as compared with traditional tidal volumes for acute lung injury and the acute respiratory distress syndrome. N Engl J Med 2000;342(18):1301-1308.

2. Bellani G, Laffey JG, Pham T, Fan E, Brochard L, Esteban A, et al. Epidemiology, patterns of care, and mortality for patients with acute respiratory distress syndrome in intensive care units in 50 countries. JAMA 2016;315(8):788-800.

3. Garnier M, Quesnel C, Fulgencio JP, Degrain M, Carteaux G, Bonnet $\mathrm{F}$, et al. Multifaceted bench comparative evaluation of latest intensive care unit ventilators. Br J Anaesth 2015;115(1):89-98.
4. ARDS definition Task force, Ranieri VM, Rubenfeld GD, Thompson BT, Ferguson ND, Caldwell E, et al. Acute respiratory distress syndrome: the Berlin definition. JAMA 2012;307(23): 2526-2533.

5. Esteban A, Frutos-Vivar F, Muriel A, Ferguson ND, Peñuelas O, Abraira V, et al. Evolution of mortality over time in patients receiving mechanical ventilation. Am J Respir Crit Care Med 2013;188(2): 220-230.

6. Wing TJ, Haan L, Ashworth LJ, Anderson J. Limiting volume with modern ventilators. Ther Adv Respir Dis 2015;9(3):75-83.

7. Brochard L, Slutsky A, Pesenti A. Mechanical ventilation to minimize progression of lung injury in acute respiratory failure. Am J Respir Crit Care Med 2017;195(4):438-442.

8. Leray V, Bourdin G, Flandreau G, Bayle F, Wallet F, Richard JC, Guérin C. A case of pneumomediastinum in a patient with acute respiratory distress syndrome on pressure support ventilation. Respir Care 2010;55(6):770-773.

9. Yoshida T, Uchiyama A, Matsuura N, Mashimo T, Fujino Y. The comparison of spontaneous breathing and muscle paralysis in two different severities of experimental lung injury. Crit Care Med 2013; 41(2):536-545

10. Yoshida T, Nakahashi S, Nakamura MA, Koyama Y, Roldan R, Torsani V, et al. Volume controlled ventilation does not prevent injurious inflation during spontaneous effort. Am J Respir Crit Care Med. doi: 10.1164/rcem.201610-1972OC.

11. Richard JC, Lyazidi A, Akoumianaki E, Mortaza S, Cordioli RL, Lefebvre JC, et al. Potentially harmful effects of inspiratory synchronization during pressure preset ventilation. Intensive Care Med 2013;39(11):2003-2010.

12. Yoshida T, Torsani V, Gomes S, De Santis RR, Beraldo MA, Costa EL, et al. Spontaneous effort causes occult pendelluft during mechanical ventilation. Am J Respir Crit Care Med 2013;188(12):14201427.

13. Kress JP, Pohlman AS, O'Connor MF, Hall JB. Daily interruption of sedative infusions in critically ill patients undergoing mechanical ventilation. N Engl J Med 2000;342(20):1471-1477.

14. Georgopoulos D, Xirouchaki N, Tzanakis N, Younes M. Driving pressure during assisted mechanical ventilation: is it controlled by patient brain? Respir Physiol Neurobiol 2016;228:69-75.

15. Doorduin J, Nollet JL, Roesthuis LH, van Hees HW, Brochard LJ, Sinderby CA, et al. Partial neuromuscular blockade during partial ventilatory support in sedated patients with high tidal volumes. Am J Respir Crit Care Med 2017;195(8):1033-1042. 